\title{
Structural Relationships among the Factors Affecting Adolescents' Happiness in OECD countries: Application of QCA method
}

\author{
Young-Chool Choi, Ji-Hyun Jang* \\ Chungbuk National University, Cheongju City, Korea, Sangmyung University, Cheonan City, Korea \\ *Corresponding author: ycchoi@cbu.ac.kr
}

Received January 12, 2015; Revised January 22, 2015; Accepted January 27, 2015

\begin{abstract}
This study aims to investigate the causal relationships among the key factors related to education that affect the happiness of adolescents, to find combinations of conditions explaining adolescents' happiness in OECD countries, and to put forward policy implications whereby OECD countries may raise their levels of adolescent happiness. The HBSC (Health Behaviour in School-aged Children) score of adolescents of OECD countries was selected as an indicator for happiness, and some independent variables such as per capita GDP, per capita educational expenditure amount were included in the subject of analysis. QCA (Qualitative Comparative Analysis) method was employed for the analysis. Research results show that there are six configurations and three selected prime implicants explaining the high happiness score of adolescents in OECD countries. Three prime implicants are TEPC*GDP*PUPTEA, tee*GDP*PRIVATEXP, and tee*tepc*gdp*privatexp. In other words, while there are a number of further steps required to obtain a more parsimonious expression, in this research the suggestions posed by the solution are six configurations and three prime implicants explaining adolescents' happiness in OECD countries. The first prime implicant is a combination of TEPC(high total per capita expenditure on education)*GDP(high per capita gdp)*PUPTEA(high ratio of students to teaching staff). The second implicant is a combination of tee(low total expenditure on education)*GDP(high per capita gdp)*PRIVATEXP(high ratio of private source expenditure on education to gdp). Finally, the third implicant is a combination of tee(low total expenditure on education)*tepc(low total per capita expenditure on education)*gdp(low per capita gdp)*privatexp(low ratio of private source expenditure on education to gdp). It is important to note that the results presented in this paper are illustrative only and need to be investigated in a more comprehensive perspective. Rather than being a limitation of QCA, consideration of alternative causal configurations are appropriate for the complexity of adolescents' happiness.
\end{abstract}

Keywords: adolescents' happiness, QCA, qualitative comparative analysis, TOSMANA

Cite This Article: Young-Chool Choi, and Ji-Hyun Jang, "Structural Relationships among the Factors Affecting Adolescents' Happiness in OECD countries: Application of QCA method.” American Journal of Educational Research, vol. 3, no. 1 (2015): 93-99. doi: 10.12691/education-3-1-16.

\section{Introduction}

Recently in the social science academia there have been active researches on happiness, and especially studies on the happiness of children-adolescents are gathering a wide range of interest. Studies on the happiness of children that were initiated in a worldwide scale by international organizations such as the United Nations Children's Fund(UNICEF) and further accelerated following the enactment of the UN Convention of the Rights of the Child in 1989. Also the children-adolescent happiness index was recognized of its importance as a basis for confirming policy objectives and inspecting accomplishments, and accordingly many researchers and organizations around the globe are conducting similar studies at present. (Ben-Arieh, 2006). An increase in such studies on children or adolescent groups reflect the rising international interest of happiness. Especially according to recent studies the happiness during one's early stages of life also influences one's overall happiness even after he or she becomes an adult(Yang, 2008), and so its importance is even further emphasized.

In this context a UNICEF study conducted in 2006 organized the children-adolescent happiness index into 6 categories: 'Material Well-Being', 'Health and Safety', 'Education', 'Peer and Family Relationship', 'Subjective Well-Being', and 'Behaviour and Risk'. This study then reorganized these categories into 18 components and 40 indicators in order to measure happiness. In specific, the 'Material Well-Being' section was formed of relative poverty, unemployed households, deficiency, the 'Health and Safety' section was of infant health, vaccination and accidental deaths, and the 'Education' section was of scholastic achievement, education participation and the changeover to employment. The 'Peer and Family Relationship' section was formed of family structures, parent relationships and peer relationships, the 'Subjective 
Well-Being' section was of health, school life and individual happiness, and the 'Behaviour and Risk' section was of health behaviour, risk behaviour and violence experiences. Therefore the children-adolescent happiness is based on a multifaceted index that can reflect its relational complexity with life(Park Jong-Il, Park Chang-Woong, Seo Hyo-Jeong, Yeom Yoo-Shik, 2010; UNICEF, 2006).

As was seen, UNICEF(2006) thought it appropriate to take a multifaceted approach towards the happiness of adolescents and endeavored to measure it. However even out of these measuring indexes the 'Education' section is a crucial factor in that the main developmental task of an adolescent is one's school learning and that the educational environment one is exposed to can determine his or her happiness, well-being and even future.(UNICEF, 2006). Considering this, a more specific and integrated approach is required to understand the happiness of adolescents. Nevertheless the education section covered by UNICEF is only formed of scholastic achievement, education participation and the changeover to employment. This only covers a narrow range and thus can only reflect a limited amount of the environmental characteristics of the education of adolescents.

As a response, this study recognizes the need for research and will reorganize the educational factors that influence the happiness of adolescents into the percentage of educational expenses(the percentage of educational expenditure out of the per capita GDP), the per capita educational expenditure amount, ratio of students to teaching staff, educational decentralization level, school life satisfaction level, and the academic maintenance percentage. The goal of this study is to clarify the structural relationship between these variables and happiness. Also, though it is not a direct educational factor the per capita GDP will be regarded as the basis for enforcing educational policies of a nation and thus this will be set as a exogenous variable. A structural relationship in which educational factors mediate the "per capita GDP $\rightarrow$ happiness" path was set.

Although educational factors can be subdivided into environmental aspects, teachers' aspects, students' aspects, parents' aspects and so on, this study restricted the OECD educational factors to those that can be objectively measured. National data presented by IMD was employed to obtain the per capita GDP, the percentage of educational expenses (the percentage of educational expenditure out of the per capita GDP) and the per capita educational expenditure amount. The ratio of students to teaching staff and the level of educational decentralization which displays the percentage of issues decided within the school out of educational decision-requiring issues, were obtained by utilizing national data reported by the OECD Education at Glance (2012, 2013). Meanwhile, results reported by the HBSC(Health Behavior in school-aged Children Survey, 2010, 2012) were employed to obtain data on school life satisfaction levels, academic maintenance percentages, and happiness.

The results of this study will help scholars studying on the happiness of adolescents or education policy decision makers understand the necessary influence factors related to increasing adolescent happiness, and will also provide important policy standards for deciding and enforcing education policies in both national and local levels.

\section{Theoretical Background}

\subsection{The Happiness of Adolescents}

Discussion on the children-adolescent happiness index originates from the Social Indicators Movement in the 1960s (Aborn, 1985). There was a plethora of studies conducted by various academic circles on social indicators during the late 1960s and early 1970s, and it was during this period which led to the introduction of various conceptual approaches towards the development of the children-adolescent happiness index (Lippman, 2007). Furthermore, the State of the World's Children report which has been published annually since 1979 by UNICEF and the UN Convention on the Rights of the Child adopted in 1989 led to an increase in international interest and researches.

Happiness is used along with terms such as well-being, satisfaction in life, subjective well-being, quality of life and so on, and its definition is used slightly differently between scholars. Kim Shin-Young and Baek HyeJeong(2008) conceptualized the relationship between the words used similarly with happiness, and stated that "happiness is the narrowest term in that it describes one's positive emotion to his or her life, subjective well-being is medium-sized term in that it is an accumulation of subjective evaluations of one's quality of life, and the subjective quality of life is the most comprehensive term in that different factors other than psychological ones such as subjective well-being can be included." Hereupon, in the following study happiness will be understood in its narrowest concept and will be defined as 'the feeling in which sufficient satisfaction and happiness is experienced in life (The National Institute of the Korean Language, 2014)'.

Related to such measurements on abstract happiness, many researchers have put their efforts in order to conduct an objective measurement. For instance, single questions such as 'How happy are you?', 'How satisfied are you with your life in overall?'(Campbell, Converse, \& Rodgers, 1976), a facial measurement method which measures one's emotional state through facial expressions(Andrews \& Withey, 1976), a happiness scale formed of two questions, 'In general how many times do you feel happy or unhappy emotions?' and 'In average how much in percentages did you feel happy' (Fordyce, 1988), a subjective happiness scale consisting of four questions and four options, 'Am I a happy person', 'Am I happy compared to my peers', 'Do I resemble one who does or does not pursue happiness and enjoy life' (Lyubomirsky \& Rose, 1997), a subjective well-being scale which measures both positive and negative emotions towards satisfaction of life (Diener, 1984), a psychological well-being scale comprising of 46 questions (Ryff, 1998), and the Oxford happiness scale (Argyle, Martin, \& Crossland, 1989) are frequently used, and there is also the well-being scale which adds social well-being to its criterion(Keyes, 2005).

In this study happiness is defined as a feeling in which sufficient satisfaction and joy is felt, and so supports Diener(1984)'s opinion which states that happiness should be evaluated based on one's subjective experience. Therefore out of the instruments used to conduct investigations on OECD 22 countries' adolescents, the questions of whether one is satisfied with his or her life 
mentioned in HBSC(Health Behavior in school-aged Children Survey, 2012) was thought to be closest to fulfilling the requirements needed to measure such concepts and happiness and thus was employed.

\subsection{Factors Affecting Educational Competitiveness}

It is generally understood that many factors can affect happiness of adolescents in a country, and many studies have indicated that a number of factors can be involved in happiness or well-being in one country. Here, we address the potential factors associated with happiness of adolescents and their interrelationships.

First, we hypothesize that per capita GDP is associated with total expenditure on education. In OECD member countries, the proportion of total expenditure on education as a percentage of GDP is relatively high, accounting for approximately 5.6 percent of GDP in 2006. The proportion of expenditure on primary and secondary education is 3.7 percent of GDP, whereas that of expenditure on higher education is 1.4 percent of GDP (OECD, 2010). The expenditure of OECD member countries on education increased by 28 percent between 2000 and 2006, reaching an average annual growth rate of 4 percent. In spite of the fact that expenditure on education nowadays accounts for a large proportion of GDP, and also has been increasing constantly, there have been few studies proving that growth in education spending leads to growth in adolescents' happiness. In the meantime, some studies (Choi, 2008; Shin and Joo, 2013) have concluded that accumulated per capita expenditure on education has positively affected happiness of people. On the basis of these research findings, this study hypothesizes that per capita GDP, total expenditure on education, and total per capita expenditure on education affect adolescents' happiness.

Second, we hypothesize that parents' concerns about education is associated with adolescents' happiness. It is important, in relation to adolescents' happiness, whether parents are strongly concerned about a student's future career or not. This is more important in Asian than in Western societies. Parental concerns about children's education can be represented by total expenditure on education burdened by the private sector. There have been few studies examining the relationships between total expenditure on education burdened by the private sector and adolescents' happiness. Here, following the work of some scholars (Choi, 2008; KEDI, 2010), we hypothesize that private-source expenditure on education as a percentage of GDP is positively associated adolescents' happiness.

Third, we hypothesize that pupil-teacher ratio can affect adolescents' happiness. The ratio of students to teaching staff is an important issue as regards the quality of education worldwide. It is assumed that the smaller the number of students a teacher can teach, the greater will be the adolescents' happiness.

In summary, we include per capita GDP, total expenditure on education as a percentage of GDP, total per capita expenditure on education, ratio of students to teaching staff, and ration of private-source expenditure on education as independent variables affecting the dependent variable, adolescents’ happiness..

\subsection{Research questions}

On the basis of the theoretical discussion above, we suggest the following research question:

What are the structural configurations among the variables affecting adolescents' happiness as a dependent variable?

\section{Research design}

\subsection{Variables}

The countries to be included in this analysis are OECD member countries. Among these, some countries are excluded because of problems with data. The variables analyzed in this research consist of five independent variables and one dependent variable. The five independent variables are: per capita GDP, total expenditure on education as a percentage of GDP, total per capita expenditure on education, ratio of students to teaching staff, and private -source expenditure on education. The one final dependent variable is adolescents' happiness. Table 1 explains the names of the variables, their measurement, and their data source.

Table 1. Variables and their sources

\begin{tabular}{|c|c|c|c|}
\hline Variable name & Mogcurnmont mothod & Dat? cource & Torodtc $\mathrm{s}, \mathrm{s}$ \\
\hline happiness(subhappy) & $\begin{array}{l}\text { subjective recognition whether satisfied by } \\
\text { one's life }\end{array}$ & $\begin{array}{l}\text { HBSC(Health Behavior in school-aged } \\
\text { Children Survey, 2012) }\end{array}$ & $11,13,15$ year olds \\
\hline per capita GDP(gdp)) & per capita GDP & $\begin{array}{l}\text { IMD World Competitiveness Yearbook } \\
\text { (2013) }\end{array}$ & National data \\
\hline $\begin{array}{l}\text { educational } \\
\text { percentage(tee) }\end{array}$ & $\begin{array}{l}\text { percentage of education expenses out of } \\
\text { per capita GDP(\%) }\end{array}$ & $\begin{array}{l}\text { IMD World Competitiveness Yearbook } \\
\text { (2013) }\end{array}$ & National data \\
\hline $\begin{array}{l}\text { per capita education expenditure } \\
\text { amount (tepc) }\end{array}$ & education expenditure per person & $\begin{array}{l}\text { IMD World Competitiveness Yearbook } \\
\text { (2013) }\end{array}$ & National data \\
\hline $\begin{array}{llll}\text { ratio of students } & \text { to teaching } \\
\text { staff(puptea) }\end{array}$ & $\begin{array}{l}\text { number of students divided by number of } \\
\text { teachers }\end{array}$ & OECD Education at Glance, (2013) & National data \\
\hline Parental concerns (privatexp) & $\begin{array}{l}\text { Ratio of private-source expenditure on } \\
\text { education to gdp }\end{array}$ & OECD, Education at a Glance( 2013) & National data \\
\hline
\end{tabular}

Note: Italic letters in parenthesis mean acronyms of the variables in Figures below.

\subsection{Research Method}

In this study, we employ Qualitative Comparative Analysis (QCA) method to discover conditions explaining adolescents' happiness in OECD countries. QCA as a method is founded on the binary logic of Boolean algebra. Each case included in the analysis is represented as a combination of causal and outcome conditions. Vink and Van Vliet (2009) describe QCA as a family of comparative techniques that aim to explain macro-social phenomena in a parsimonious way while working with 
small-to medium-size data sets. Rihoux (2006) suggests that small studies $(n<30)$ are most suited to dealing with dichotomous subjects (few conditions), where a particular focus can be directed to individual cases. As Wagemann and Schneider (2010) states, no method is per se superior. Rather, its usefulness is determined by its fit to the research problem at hand. In this regard, QCA is considered as a good tool to discover conditions affecting happiness of adolescents in 22 OECD countries.

The first state in a QCA, like other methods is to show descriptive statistics included in the analysis. Then, it is necessary to standardize the original values of each variable in order to minimize the subjectivity occurring in the analysis process. The next stage is to build a truth table with data for selected cases regarding the causal conditions and the outcome variables. Truth tables list the logically possible combinations of conditions and the outcome associated with each combination (Poveda, 2013). Next, investigation of a truth table by itself allows for a study of diversity, showing which configurations are common and which ones do not happen or happen very seldom. In this process, Venn diagrams helps us understand the logical relationships between conditions. Finally, conditions explaining adolescents' happiness are derived, and prime implicants are suggested.

\section{Research Results}

\subsection{Descriptive Statistics}

As can be seen in <Table $2>$ the average per capita GDP of the OECD 22 countries is 42861, the average educational expenditure percentage 5.85, the average per capita educational expenditure 2354.20, the average ratio of student to teaching staff 11.95 , the average privatesource expenditure on education to GDP is 0.6, and the average level of happiness 85.76.

Table 2 shows the standardized values of variables relating to adolescents' happiness in OECD countries.

Table 2. Mean and standard deviations

\begin{tabular}{|c|c|c|c|c|}
\hline \multirow{2}{*}{ Variable } & \multicolumn{4}{|c|}{22 countries } \\
\hline & Min. & Max. & Mean & SD \\
\hline per capita GDP (gdp) & 13540.00 & 97255.00 & 42861 & 20239 \\
\hline per capita education expenditure(tepc) & 717.00 & 4682.00 & 2354.20 & 1086.51 \\
\hline ratio of students to teaching staff(puptea) & 7.50 & 17.60 & 11.95 & 2.51 \\
\hline Happiness(subhappy) & 66.60 & 94.20 & 85.76 & 5.40 \\
\hline
\end{tabular}

Table 3. Standardized values of each variable

\begin{tabular}{|c|c|c|c|c|c|c|c|}
\hline country1 & tee & tepc & gdp & privatexpsd & pupteasd & pisasd & subhappysd \\
\hline Korea & 0.12 & 0.01 & 0.11 & 1 & 1 & 1 & 0 \\
\hline Switzerl & 0.26 & 0.62 & 0.81 & 0 & 0.42 & 0.68 & 0.75 \\
\hline Netherla & 0.4 & 0.46 & 0.44 & 0.29 & 0.57 & 0.69 & 0.93 \\
\hline Finland & 0.55 & 0.51 & 0.43 & 0.03 & 0.49 & 0.83 & 0.66 \\
\hline Poland & 0.29 & 0 & 0 & 0.26 & 0.23 & 0.71 & 0.3 \\
\hline Belgium & 0.5 & 0.42 & 0.4 & 0.1 & 0.14 & 0.57 & 0.29 \\
\hline Germany & 0.05 & 0.25 & 0.36 & 0.26 & 0.39 & 0.64 & 0.66 \\
\hline Austria & 0.36 & 0.43 & 0.43 & 0.06 & 0.15 & 0.45 & 0.74 \\
\hline Ireland & 0.33 & 0.42 & 0.41 & 0.13 & 0.6 & 0.64 & 0.7 \\
\hline Denmark & 0.88 & 0.84 & 0.55 & 0.1 & 0.26 & 0.42 & 0.5 \\
\hline Czech Re & 0 & 0.03 & 0.08 & 0.19 & 0.61 & 0.45 & 0.65 \\
\hline France & 0.48 & 0.41 & 0.36 & 0.16 & 0.62 & 0.44 & 0.65 \\
\hline United K & 0.67 & 0.38 & 0.26 & 0.23 & 0.87 & 0.48 & 0.55 \\
\hline Iceland & 1 & 0.55 & 0.35 & 0.23 & 0 & 0.25 & 0.57 \\
\hline Norway & 0.36 & 1 & 1 & 0 & 0.13 & 0.39 & 0.62 \\
\hline Portugal & 0.57 & 0.14 & 0.11 & 0.13 & 0.04 & 0.29 & 0.63 \\
\hline Italy & 0.02 & 0.17 & 0.27 & 0.13 & 0.28 & 0.31 & 0.78 \\
\hline Spain & 0.19 & 0.17 & 0.22 & 0.23 & 0.27 & 0.31 & 1 \\
\hline United S & 0.62 & 0.49 & 0.42 & 0.68 & 0.47 & 0.34 & 0.71 \\
\hline Sweden & 0.69 & 0.58 & 0.52 & 0.06 & 0.08 & 0.21 & 0.72 \\
\hline Hungary & 0.36 & 0 & 0.01 & 0 & 0.23 & 0.27 & 0.36 \\
\hline Greece & 0 & 0.07 & 0.16 & 0 & 0.03 & 0 & 0.88 \\
\hline
\end{tabular}

\subsection{Dichotomization and Truth Tables}

Table 4 below shows dichotomized value, 0 or 1 of each variable. To transform scale data to stepped variable suitable for QCA analysis, thresholds must be set to recode the data. TOSMANA software program used in this analysis provides a calibrated threshold. Table 4 shows dichotomized value of each variable based on the TOSMANA threshold function. 
Table 4. Truth table of the relationship between dependent and independent variables

\begin{tabular}{|c|c|c|c|c|c|c|}
\hline country & teesd & tepcsd & gdpsd & privatexpsd & pupteasd & subhappysd \\
\hline Korea & 0 & 0 & 0 & 1 & 1 & 0 \\
\hline Switzerl & 0 & 1 & 1 & 0 & 1 & 1 \\
\hline Netherla & 1 & 1 & 1 & 1 & 1 & 1 \\
\hline Finland & 1 & 1 & 1 & 0 & 1 & 1 \\
\hline Poland & 0 & 0 & 0 & 1 & 0 & 0 \\
\hline Belgium & 1 & 1 & 1 & 0 & 0 & 0 \\
\hline Germany & 0 & 0 & 1 & 1 & 1 & 1 \\
\hline Austria & 1 & 1 & 1 & 0 & 0 & 1 \\
\hline Ireland & 0 & 1 & 1 & 1 & 1 & 1 \\
\hline Denmark & 1 & 1 & 1 & 0 & 0 & 0 \\
\hline Czech Re & 0 & 0 & 0 & 1 & 1 & 0 \\
\hline France & 1 & 0 & 1 & 1 & 1 & 0 \\
\hline United K & 1 & 0 & 0 & 1 & 1 & 0 \\
\hline Iceland & 1 & 1 & 0 & 1 & 0 & 0 \\
\hline Norway & 1 & 1 & 1 & 0 & 0 & 0 \\
\hline Portugal & 1 & 0 & 0 & 1 & 0 & 0 \\
\hline Italy & 0 & 0 & 0 & 1 & 1 & 1 \\
\hline Spain & 0 & 0 & 0 & 1 & 0 & 1 \\
\hline United S & 1 & 1 & 1 & 1 & 1 & 1 \\
\hline Sweden & 1 & 1 & 1 & 0 & 0 & 1 \\
\hline Hungary & 1 & 0 & 0 & 0 & 0 & 0 \\
\hline Greece & 0 & 0 & 0 & 0 & 0 & 1 \\
\hline
\end{tabular}

Table 5. The completed truth table

Truth Tables

\begin{tabular}{|c|c|c|c|c|c|c|}
\hline v1: & teesd_1 & v2: & tepcsed_1 & & & \\
\hline v3: & gdpsd_1 & v4: & privatexpsd_1 & & & \\
\hline v5: & pupteasd-1 & & & & & \\
\hline 0 : & supteasd_1id: & country & & & & \\
\hline v1 & v2 & v3 & v4 & v5 & 0 & id \\
\hline 0 & 0 & 0 & 1 & 1 & $\mathrm{C}$ & Korea, Czech Re, Italy \\
\hline 0 & 1 & 1 & 0 & 1 & 1 & Switzerl \\
\hline 1 & 1 & 1 & 1 & 1 & 1 & Netherla, United S \\
\hline 1 & 1 & 1 & 0 & 1 & 1 & Finland \\
\hline 0 & 0 & 0 & 1 & 0 & $\mathrm{C}$ & Poland, Spain \\
\hline 1 & 1 & 1 & 0 & 0 & $\mathrm{C}$ & Belgium, Austria, Denmark, Norway, Sweden \\
\hline 0 & 0 & 1 & 1 & 1 & 1 & Germany \\
\hline 0 & 1 & 1 & 1 & 1 & 1 & Ireland \\
\hline 1 & 0 & 1 & 1 & 1 & 0 & Francd \\
\hline 1 & 0 & 0 & 1 & 1 & 0 & United K \\
\hline 1 & 2 & 0 & 1 & 0 & 0 & Iceland \\
\hline 1 & 0 & 0 & 1 & 0 & 0 & Portugal \\
\hline 1 & 0 & 0 & 0 & 0 & 0 & Hungary \\
\hline 0 & 0 & 0 & 0 & 0 & 1 & Greece \\
\hline
\end{tabular}

Result:

TEPCSD_1*GDPSD_1*PUPTEASD_1* tessd_1*GDPSD_1*PRIVATEXPSD_1*PUPTEASD_1*

tessd_1*tepcsd_1*gdpsd_1*privatexpsd_1*pupteasd_1

(Switzed*Netherla, United S*Finland+Ireland) (Germany*Ireland) (Greece)

Simplifying Assumptions:

Number of Simplifying Assumpyions:0

With values of [0] and [1] assigned to study conditions, OECD countries can then be recorded, resulting in a truth table (Table 5).

In a truth table produced by using TOSMANA 1.3 program, various conditions can be compared against each other and ideally against an outcome, adolescents' happiness level. Venn diagrams below illustrate the logical relationships between conditions. Each space in a diagram can be color coded, shaded or patterned. Figure 1 is a graphical depiction of the configurations from the

truth values presented in Table 4 and was produced by TOSMANA 1.3's 'visualizer' tool.

In the diagram, [1], or a positive outcome, is shaded green, [0], or a negative outcome, is shaded lilac and [C], or contradictory configurations, are patterned with green and lilac stripes, Contradictory configurations occur in cases where some combinations of conditions result in a [0] outcome, but others result in a [1] outcome (Wiechula, 2012). Blank white spaces are logical remainders [R], or combinations of conditions that have not been observed. 
For example, the lower left space the notation 01000 and highlights the absence of any combination of conditions associated with a positive outcome. Table 6 below shows six configurations associated with high level of adolescents' happiness in OECD countries.

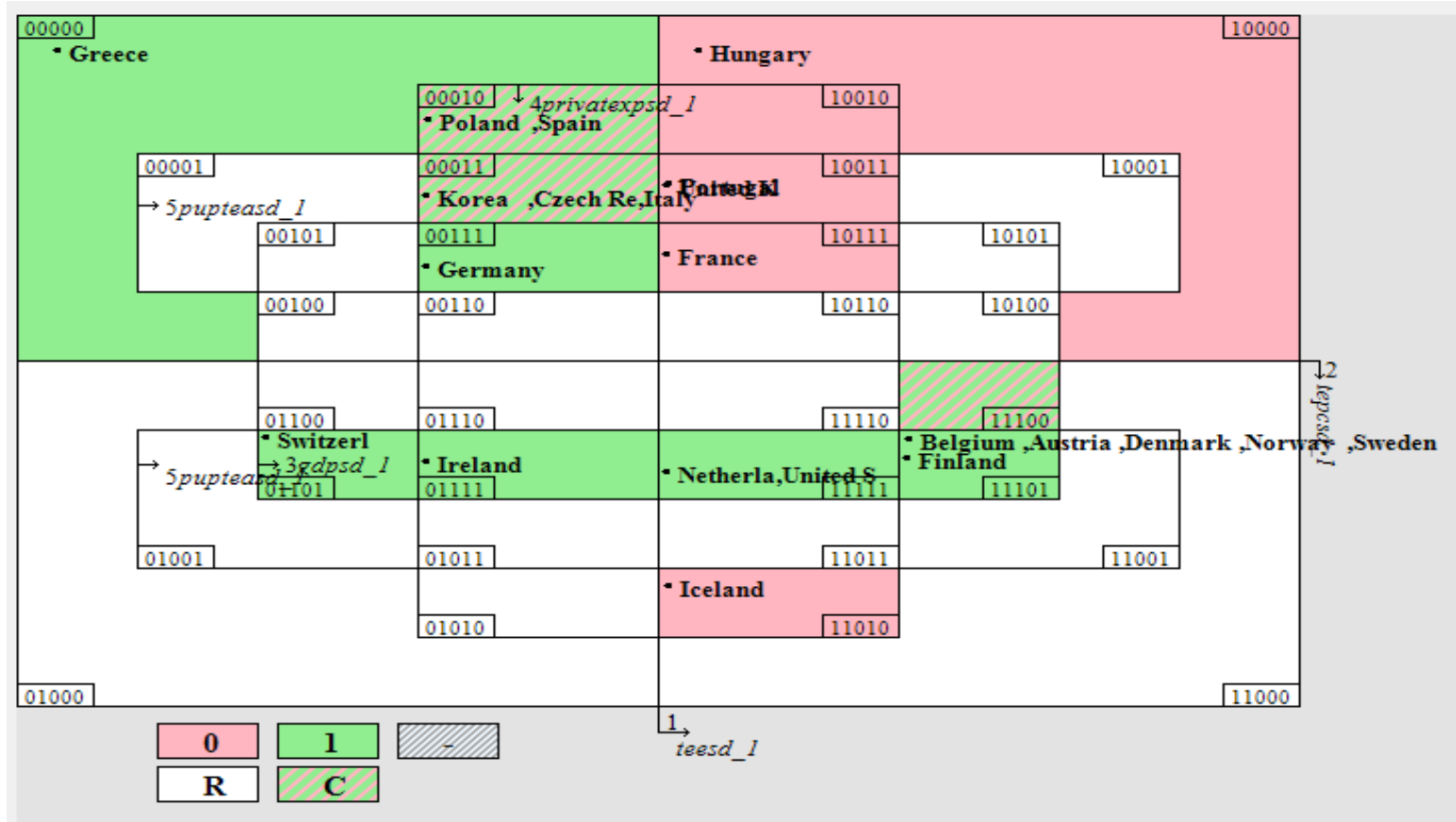

Figure 1. Venn diagram output from the TOSMANA program

Table 6. Configurations associated with adolescents' happiness

\begin{tabular}{lll}
\hline Configurations & Country & Remarks \\
\hline $\begin{array}{l}\text { tee(0)*Tepc(1)*Gdp(1)*privatexp(0) } \\
\text { *Puptea(1) }\end{array}$ & Switzerland & 1 country \\
$\begin{array}{l}\text { Tee(1)*Tepc(1)*Gdp(1)*Privatexp(1)* } \\
\text { Puptea(1) }\end{array}$ & Netherlands, US & 2 countries \\
$\begin{array}{l}\text { Tee(1)*Tepc(1)*Gdp(1)privatexp(0)* } \\
\text { Puptea(1) }\end{array}$ & Finland & 1 country \\
$\begin{array}{l}\text { tee(0)*tepc(0)*Gdp(1)*Privatexp(1)* } \\
\text { Puptea(1) }\end{array}$ & Germany & 1 country \\
tee(0)*Tepc(1)*Gdp(1)*Privatexp(1)* & Ireland & 1 country \\
$\begin{array}{l}\text { Puptea(1) } \\
\text { tee(0)*tepc(0)*gdp }(0) * \operatorname{privatexp}(0)^{*} \\
\text { puptea(0) }\end{array}$ & Greece & 1 country \\
\hline
\end{tabular}

Table 7. Prime implicants

\begin{tabular}{ccc}
\hline Prime implicants & Country & Remark \\
\hline TEPC*GDP*PUPTEA & $\begin{array}{c}\text { Switzerland, Netherland, United } \\
\text { States, Finland, Ireland }\end{array}$ & 5 \\
Tee*GDP*PRIVATEXP & Germany, Ireland & 2 \\
tee*tepc*gdp*privatexp & Greece & 1 \\
\hline
\end{tabular}

Note: capital letter 1(positive), small letter (negative)

Table 6 shows that there are six configurations explaining high score of adolescents' happiness in OECD countries. Here upper case letters indicate a value of 1 (positive), and lower case letters indicate a value of 0 (negative). As can be seen in Table 7, in this analysis three prime implicants explaining adolescents' happiness in OECD countries are found. A prime implicant is usually a set of conditions joined by the Boolean 'AND'[*] operator, suggesting a relationship or solution between the conditions (Donnelly, 2013: 11). Because prime implicant means the most minimal solution minimizing truth table results, three prime implicants in this analysis can give useful information for other countries, which have low adolescent's happiness score, to be able to benchmark the OECD countries with high score of adolescents' happiness.
In Figure 1, cases of, Switzerland, Netherland, United States, Finland, Ireland, Germany, and Greece are related to solution, which for example would be expressed as: TEPC*GDP*PUPTEA+ tee*tepc*gdp*privatexp.

In other words, conditions of TEPC*GDP*PUPTEA, Tee*GDP*PRIVATEXP, and tee*tepc*gdp*privatexp are called prime implicants of the six configurations produced. To sum up, three prime implicants are combinations of important conditions determining high level of adolescents' happiness in OECD countries.

\section{Conclusion}

This paper emphasizes the importance of adolescents' happiness, describes the usefulness of QCA in examining what causal conditions can influence high level of adolescents' happiness in OECD countries, and attempts to discover configurations associated with adolescents' happiness and simple prime implicants relating to the solution. In this analysis, six configurations affecting adolescents' happiness and three prime implicants, which are sets of conditions suggesting a relationship or solution between the conditions, are derived. QCA is an alternative approach to analysis in adolescents' happiness that involves truth tables, Boolean algebra and search for a greater understanding of causal conditions. The use of QCA has been rarely reported in adolescents' happiness studies, and is likely to be conceptual and paradigmatic challenges to its adoption in some settings.

Proposals for follow-up studies are as follows. Only 22 out of the 34 OECD countries were all included in the data reported from IMD, OECD and HBSC, and thus in follow-up studies data that can include more countries should be considered. Also, to derive educational implications 
to enhance the happiness of adolescents in OECD countries in an integrated perspective there is a need to conduct researches by including other educational factors.

\section{Acknowledgements}

This work was supported by the National Research Foundation of Korea Grant funded by the Korean Government (NRF-2012-413-B0031).

\section{References}

[1] Aborn, M. (1985). Statistical legacies of the social indicators movement. Paper presented at the Annual meeting of the American Statistical Association. Las Vegas, Nevada.

[2] Andrews, F. M., \& Withey, S. B. (1976). Social indicators of wellbeing. New York and London: Plenum.

[3] Argyle, M., Martin, M., \& Crossland J.(1989). Happiness as a function of personality and social encounters. In J. P. Forgas, \& J. M. Innes(Eds.)., Recent advances in social psychology: An International perspective (pp.189-203). North-Holland: Elsevier.

[4] Ben-Arieh, A. (2006). Measuring and Monitoring the Well-being of Young Children around the World. Paper commissioned for EFA Global Monitoring Report 2007. Storing Foundations: Early Childhood Care and Education.

[5] Campbell, A. Converse, P. E., \& Rodgers, W. L. (1976). The quality of American life. New York: Sage.

[6] Diener, E. (1984). Subjective well-being. Psychological Bulletin, 193, 542-575.

[7] Diener, E. (1984). Subjective wellbeing. Psychological Bulletin, 95, 542-575.

[8] Donnelly, F., Wiechula, R. (2013). An example of qualitative comparative analysis in nursing research. Nurse Researcher. 20, 6, 6-11.

[9] Fordyce, M. W. (1988). A review of research on the happiness measure: a sixty second index of happiness and mental health. Social Indicators Research, 20, 355-381.

[10] HBSC (2010). Health Behavior in school-aged Children Survey.

[11] HBSC (2012). Health Behavior in school-aged Children Survey.

[12] IMD (2012). World Competitiveness Yearbook. Geneva: IMD.

[13] IMD (2013). World Competitiveness Yearbook. Geneva: IMD.
[14] Keyes, C. L. M. (2005). The subjective well-being of America's youth: Toward a comprehensive assessment. Adolescent and Family Health, 4, 1-32.

[15] Kim Shin-Young \& Baek Hye-Jeong. (2008). Developing Happiness Index for Korean Adolescents. Korean Sociology, 42(6), 140-173.

[16] Lippman, L. H. (2007). Indicators and indices of child well-being: a brief American history. Social Indicators Research, 83, 39-53.

[17] Lyubomirsky, S., \& Ross, L. (1997). Hedonic consequences of social comparison: A contrast of happy and unhappy people. Journal of Personality and Social Psychology, 73, 1141-1157.

[18] OECD (2008). www.oecd.or/edu/eag

[19] OECD (2010). Education at a Glance. Paris: OECD.

[20] OECD (2012). Education at a Glance. Paris: OECD.

[21] OECD (2013). Education at a Glance. Paris: OECD.

[22] Park Jong-Il, Park Chang-Woong, Seo Hyo-Jeong, Yeom YooShik. (2010). An International Comparison of Childern's Happiness. Korean Sociology, 44(2), 121-154.

[23] Poveda, A.C. (2013). Qualitative comparative analysis: an application for industry. Qual Quant, 47, 1315-1321.

[24] Rihoux, B. (2006). Qualitative comparative analysis (QCA) and related systematic methods: recent advances and remaining challenges for social sciences research. International Sociology. 21 , 5, 679-706.

[25] Ryff, C.D., \& Singer, B. (1998). The contours of positive human health. New York: Oxford University Press.

[26] The National Institute of Language (2014). Standard Korean Encyclopedia. http://stdweb2.korean.go.kr/search/List_dic.jsp (searched in 18 June 2014).

[27] UNICEF (2006). Comparing Child Well-being in OECD Countries: Concepts and Methods. Innocent Working Paper.

[28] Vink MP, Van Vliet O. (2009). Not quite crisp, not yet fuzzy? Assessing the potential and pitfalls of multi-value QCA. Field Methods, 21, 3, 265-289.

[29] Yang, Y. (2008). Social Inequalities in happiness in the U.S. 19722004: An Age-Period-Cohort Analysis. American Sociological Review, 73(2), 204-226.

[30] Wagemann, C., Schneider, C. (2010). Qualitative comparative analysis(QCA) and fuzzy sets: agenda for a research approach and a data analysis technique. Comparative Sociology, 9, 376-396.

[31] Wiechula, D. (2012). An example of qualitative comparative analysis in nursing research. Nurse Researcher, 206, 6-11. 